\title{
Recent Approaches for Novel Treatment for Pulmonary Diseases
}

\author{
Bhavna*, Deepika Sharma and Kartik Goyal \\ Faculty of Pharmacy, DIT University, India
}

Submission: December 19, 2017; Published: January 23, 2018

*Corresponding author: Bhavna, Faculty of Pharmacy, DIT University, India, Tel: 7500367740; 9690596819, Email: bhavnano@gmail.com

\begin{abstract}
Abstact
Pulmonary drug delivery system (PDDS) remains an important route for administration of different types of drugs. Pulmonary route has been concerned for scientific and biomedical importance in past years for treatment of lung diseases. Drug delivery by the pulmonary route has evolved to be one of the most widely used systemic or local drug delivery approach. The drug delivery systems for the treatment of lungs diseases are increased due to their prospects for localized therapy in the lungs. Pulmonary route as one important aspect which makes a possibility to deposit drugs more site-specific and targeting of drugs, as well as enhancing the local drug activity while reducing systemic side effects and firstpass metabolism. This review detailed discusses the physiological (technical) and efficacy aspects of the novel pulmonary route of drug targeting system. The review also focused on the mechanisms of pulmonary drug administration along with compatibility of the excipient employed, uses of the various devices, and new techniques of particulate dosage manufacturing. Hence, the better understanding of complexes and object facing the development of PDDs offer an opportunity to the pharmaceutical scientist in minimizing the clinical and technical gaps.
\end{abstract}

Keywords : Pulmonary delivery; Nebulizers; MDI; DPI; Novel formulation; Applications

\section{Introduction}

Pulmonary drug delivery system has been widely used for the treatment of lung diseases and is acclaimed for the asthma treatment and chronic obstructive pulmonary diseases. This system is a needle free technique. The origin of inhaled therapy seen in 4000 years ago in India, where patient smoked the Atropa belladonna leaves to suppress cough. In the early 20th century, asthmatics smoked asthma cigarettes that contain stramonium powder mixed with tobacco to treat the symptoms of their disease [1]. But administration of drug by this route is technically challenging because oral deposition can be high, and variation inhalation techniques may affect the quantity of the drug delivered to the lungs. Delivery of locally acting drugs to the site of action reduce the amount of dose needed to produce the pharmacological action but now the lungs have been studied as a possible route to administer the treatment of systemic disease like diabetes mellitus, angina pectoris, cancer, bone disorders, migraine, tuberculosis, acute lung injury and others. Pulmonary delivery is apprehended by various ways like aerosols, Metered dose inhaler systems (MDIs), Dry powder inhalers (DPI) and Nebulizers. These types of system may contain Nano formulations like microemulsions, micelles, bio-degradable nanoparticles and liposomes.

According to the need we have numerous types of dosage forms like controlled release, sustained release or immediate release. The sustained release dosage forms are favoured over the uncoated, immediate release due to the same reasons like increase in the local effects on the use at the site of infection, need of relatively small doses for the effective therapy and reduction in systemic exposure due to local application leads to reduction of adverse effects. Some scientists are annoying to evaluate the use of a sustained release form of inhaled rifampin for TB therapy. The pulmonary drug delivery field is efficacious, stupendous and advanced technique in today's applied pharmaceutical research $[2,3]$.

\section{Chronic Lung Disease}

It includes a wide variety of persistent pulmonary disorders, such as asthma, chronic obstructive pulmonary disease (COPD), cystic fibrosis, pulmonary tuberculosis, idiopathic pulmonary fibrosis (IPF) and lung cancers [4,5]. Some of these diseases are irreversible and often fatal, and no treatments have been shown to be effective for completely restoring lung functions. Approximately 300 million and 210 billion people in the world are currently estimated to suffer from the two most prevalent diseases, asthma and COPD, respectively [6,7]. Pulmonary tuberculosis is also a frequently found infectious disease with 8.6 million chronic case reported in 2012 [8,9]. Traditional pharmacotherapy for chronic lung diseases can be classified into different types according to forms of therapeutic agents. A variety of chemical drugs, peptides, antibodies, and genetic molecules (eg. SiRNA, shRNA and miRNA) have been employed to treat the chronic lung diseases [10-12]. Unfortunately, most of chronic lung disease cannot be completely cured by 
pharmacotherapy alone. In cases of asthma, controlling the symptoms is the only available current option. Likewise, steroids, bronchodilators, pirfenidone, and nintedanib are currently used for the management of COPD or IPF, but no effective treatments are available to fully cure these types of diseases [13].

\section{Pulmonary Embolism (PE)}

It is a blockage of an artery in the lungs by a substance that have travelled from elsewhere in the body through the bloodstream. Pulmonary embolism usually results from a blood clotting in the leg that moves to the lung. The risk of blood clotting increased by cancer, prolonged bed rest, smoking, stroke, obesity, pregnancy and after some types of surgery. Some cases are due to the embolization of air, fat or amniotic fluid. Diagnosis is based on signs and symptoms in combination with test results. Diagnosis is based on signs and symptoms in combination with test results. If the risk is low, a blood test ' $\mathrm{D}$-dimer' may rule out the condition. Otherwise a perfusion scan or ultrasound of legs may confirm the diagnosis. Together deep vein thrombosis and $\mathrm{PE}$ are known as venous thromboembolism. Because pulmonary embolism almost always occurs in conjunction with deep vein thrombosis, most doctors refers to the two conditions together as venous thromboembolism. Signs include low blood oxygen levels, rapid breathing, rapid heart rate and sometimes a mild fever. Severe cases can lead to passing out, abnormally low blood pressure and sudden death. Symptoms may also include breath shortness, chest pain upon breathing in, and coughing up blood. Symptoms of a blood clot in the leg may also be present such a red, warm, swollen and painful leg.

\section{Advantages of Pulmonary Drug Delivery System}

a. Helps in minimizing the dose of API molecule used for oral routes i.e. drug content of one $4 \mathrm{mg}$ tablet of salbutamol equals to 40 doses of meter doses [14].

b. Degradation of drug by liver is avoided [15].

c. Onset of action is very rapid and provides local action within the respiratory tract [16].

d. Reduces extracellular enzyme levels compared to GI tract due to the big surface area of alveolar [17]

e. It is needle free pulmonary delivery [18].

f. Inhaled drug delivery puts drug where it is needed [19].

g. Allows for a reduction in systemic side-effects.

h. Reduces evasion of first pass hepatic metabolism by absorbed drug.

i. Inhaling helps to avoid gastrointestinal tract problems such as poor solubility, low bioavailability, gut irritability unwanted metabolites, food effects and dosing variability.

j. It provides a non-invasive method of delivering drugs into the bloodstream for those molecules that can only be delivered by injection. These include proteins and peptides, such as insulin for diabetes or interferon beta for multiple sclerosis and many of the drugs developed in recent years by biotechnology companies $[14,18]$.

\section{Limitations of Pulmonary Drug Delivery System}

a. Drug absorption may be limited by the physical barrier of the mucus layer.

b. Patient may have some problems using the pulmonary drug delivery devices correctly.

c. Oropharyngeal deposition gives local side effect.

d. The duration of activity is often short-lived due to the rapid removal of drug from the lungs or due to drug metabolism [16,20].

\section{Mechanism and Ways of Pulmonary Drug Administration}

In the course of the most recent decade, the systemic absorption of a board scope of therapeutic agents after pulmonary application has been shown in animals and also in people. Through pulmonary course, the medication can be controlled by two essential modes; to start with, intranasal organization, which has anatomical impediment, for example, narrows airway lumen, second, oral inhalative organization. By oral inhalative organization obviously better outcomes can be normal as it permits controlling small particles with a concentration loss of just $20 \%$ in correlation with $85 \%$ by nasal route. Oral inhalative organization can again be delegated intratracheal instillation and intratracheal inhalation. The most well-known technique utilized as a part of research facility is the intratracheal inhalation. In the intratracheal instillation, a little measure of medication arrangement or scattering is conveyed into the lungs. The most well-known strategy utilized as a part of labs is the intratracheal instillation. In the intratracheal instillation, a little measure of drug solution or dispersion is conveyed into the lungs by an exceptional syringe. This gives a quick and quantifiable technique for drug conveyance to the lungs. The localized drug deposition is accomplished with a relatively small absorptive range. In this way, the instillation procedure is much basic, non-costly, and has non uniform drug distribution. In preclinical creature (animals) studies intratracheal instillation has as often as possible been utilized to evaluate the pulmonary absorption and systemic bioavailability, particularly as to the exact dosing and viability related with this technique. However, intratracheal instillation is not a physiological route for application, and results got from these reviews may not be transferable to aerosol applications in people.

Unexpectedly, inhalation strategy utilizes aerosol system by which we can get more uniform distribution with incredible penetration. However, this technique is all the more expensive and hard to quantify the correct dose in lungs. The deposition of drug by aerosol organization in the pulmonary airway route 
mainly has three systems: - gravitation, sedimentation, inertial impactation, and diffusion. If the drug molecule size is nearly greater, then, deposition happens by initial two mechanisms where, either sedimentation happens because of gravitational force or inertial impaction happens because of hyperventilation. At the point when the molecule size is littler they deposit mainly by diffusion mechanism, which in turn is depends on the Brownian movement. Aside from the pulmonary morphological aspects and ventilatory parameters size of the particles or droplets and the geometry is very essential. The size of particles or droplet in term of diameter along with the surface electrical charges, shape of the particulate matter it is a fiber and hygroscopy likewise having significant impact on drug deposition through pulmonary route. The term mass middle aerodynamic diameter is utilized and it relies on upon size, shape, and thickness of the particulate system.

\section{Recent Approaches For Pulmonary Drug Delivery System $[1,2]$}

\section{Low Efficiency of Inhalation System}

The major challenge in pulmonary drug delivery is the low efficiency of presently available inhalation systems. Ideal aerosol particle size is very important for deep lung delivery (pulmonary drug delivery). Since if the particles are too small, the optimum particle size for deep lung deposition is $1-5 \mathrm{~mm}$, they will be easily exhaled, and if the particle size is too large, they effects on the oropharynx and larynx.

\section{Less Drug Mass Per Puff}

To get adequate effects by the pulmonary drug delivery system the delivery of many drugs which require milligram doses but with most existing systems, the total amount of drug per puff transferred to the lower respiratory tract is too low (less than $1000 \mathrm{mcg}$ ).

\section{Poor Formulations Stability for Drugs}

Most traditional small molecule asthma drugs are crystalline in nature, comparatively moisture resistant in the dry molecules. Whereas in the case of corticosteroids, which are unstable in liquid state, amorphous, and highly moisture sensitive in the dry state.

\section{Improper Dosing Reproducibility}

The main reason for poor dosing reproducibility is worsening of diseases, problem in device, and instability of formulation. To get maximum dose reproducibility patient education play important role.

Factors Which Affecting Absorption and Bioavailability of Pulmonary Drug Delivery System [21]

Various factors that may affect pulmonary absorption rate and bioavailability are listed in Table 1.
Table 1: Various factors that may affect pulmonary absorption rate and bioavailability

\begin{tabular}{|c|c|c|}
\hline Device and Formulation & Drug & Physiology \\
\hline $\begin{array}{l}\text { Particle Properties (Size, } \\
\text { Density, Shape, Charge) }\end{array}$ & $\begin{array}{l}\text { Dissolution Rate, } \\
\text { Solubility }\end{array}$ & $\begin{array}{l}\text { Breathing Pattern } \\
\text { Blood Flow }\end{array}$ \\
\hline Deposition Pattern & Lipophilicity & Airway Morphology \\
\hline Excipients & Molecular Weight & Surface Area \\
\hline Concentration & Charge & $\begin{array}{l}\text { Mucociliary } \\
\text { Clearance }\end{array}$ \\
\hline Osmolality & $\begin{array}{l}\text { Hydrogen Bonding } \\
\text { Potential }\end{array}$ & Lung Surfactant \\
\hline ph & Conformation & $\begin{array}{c}\text { Epithelial } \\
\text { Permeability }\end{array}$ \\
\hline \multirow{3}{*}{ Dose Size/Volume } & Chemical Stability & $\begin{array}{l}\text { Endothelial } \\
\text { Permeability }\end{array}$ \\
\hline & \multirow{2}{*}{$\begin{array}{l}\text { Enzymatic } \\
\text { Stability }\end{array}$} & $\begin{array}{c}\text { Enzymatic/ } \\
\text { Metabolic Activity }\end{array}$ \\
\hline & & Disease \\
\hline & & Tissue Composition \\
\hline Viscosity & $\begin{array}{c}\text { Aggregation/ } \\
\text { Complex Binding }\end{array}$ & $\begin{array}{c}\text { Alveolar } \\
\text { Macrophages }\end{array}$ \\
\hline
\end{tabular}

Factors which Affecting Absorption and Bioavailability ff Pulmonary Drug Delivery System [21]

\section{Formulations}

The drugs may be inhaled by pulmonary route utilizing two techniques: aerosol inhalation and intratracheal instillation. By applying aerosol technique, we could obtain more uniform distribution with maximum extent of penetration into the peripheral or the alveolar region of the lung, but this costs more and also faced with difficulty in measuring the exact dose inside the lungs. In contrary to this, instillation process is much simple, not expensive and has non-uniform distribution of drugs [22].

\section{Devices for Pulmonary Drug Delivery Systems and There Advances}

Following types of inhalation devices are present:

\section{Nebulizers}

There are two types of nebulizer systems which are widely used as aerosolize drug solutions or suspensions for drug delivery to the respiratory tract i.e. the ultrasonic nebulizer and the air jet nebulizer. In ultrasonic nebulizers, ultrasound waves are found in an ultrasonic nebulizer by a ceramic piezoelectric crystal that vibrates when electrically excited. The aerosol produced by an air jet nebulizer is generated when compressed air is forced through an orifice; an area of low pressure is formed where the air jet exists. Nebulizers are useful for the treatment of acute asthma and emergency care unit or for treating patients with severe asthma at home. The nebulizer can transport more drugs to the lungs than metered dose inhalers (MDI) or dry powdered inhalers (DPI), the most common disadvantage of nebulizer are lack of possibility, higher costs of drug delivery 
as a result of the larger need for assistance from health care professionals, and the need for higher drug doses to achieve a therapeutic result $[2,4,23,24]$.

\section{Trends In Nebulizers Technology [25]}

a. Recent advancements in liquid aerosol innovation consolidate the advantages of MDIs and nebulizers are called metered dose liquid inhalers. The big advantage that every one of these systems focus for the reduced velocity of the aerosol. Liquid inhalers applying the idea of a low velocity aerosol are frequently alluded to as 'soft mist inhalers'.

b. Wet nebulisation goes for the era of mono disperses aerosols. The nonattendance of propellants in the formulation by applying aqueous drug formulated causes a reduction in the residual volume after nebulisation and an enhanced portability compared and nebulizers.

c. Now-a-days various marketed formulations of nebulizers are available in market. Some of such formulations are listed in Table 2.

Table 2 : Marketed formulations of Nebulizers.

\begin{tabular}{|c|c|c|}
\hline Brand & Drug & Manufacturer \\
\hline Accuneb & Albuterol Sulfate & Dey Pharm \\
\hline Xopenex & Levoalbuterol HCl & Sunovion Pharm \\
\hline DuoNeb & $\begin{array}{c}\text { Ipratropium } \\
\text { Bromide, Albuterol } \\
\text { Sulfate }\end{array}$ & Dey Pharm \\
\hline Perforomist & Formoterolfumarate & Dey Pharm \\
\hline SteriNeb & Budesonide & Teva Pharmaceuticals \\
\hline Pulmozyme & Doranase Alpha & Genentech lnc. \\
\hline Caysten & Azteronam & Gilead Sci. \\
\hline
\end{tabular}

\section{Metered Dose Inhalers (MDIs)}

MDI is a complex system designed to provide a fine mist of medicament, generally with an aerodynamic particle size having less than 5 microns, for inhalation directly to the airways for the treatment of respiratory diseases such as asthma and COPD $[1,25]$. They can be given in the form of suspension or solution. They consist of a micronized form of the active pharmaceutical ingredient (API) in a propellant under pressure with surfactants to prevent clumping of API molecule. Lubricants for the valve mechanism and other solvents are the other constituents. When the device is pressed, the propellant gets disclosed to atmospheric pressure, which leads to aeroionisation of the drug. As it travels through the air, the aerosol warms up leading to evaporation of the propellant that reduces the particle size to the specific range. The fraction of drug to the airways ranges from 5-15\% [26]. In 1990, attempts were actively made of reformulate MDIs as a result of mandatory ban on the use of propellant chlorofluorocarbons, which have been concerned in the depletion of the Earth's ozone layer. Optional propellants, such as hydrofluoroalkane 134a (HFA-134), have be considered for their potentials to change CFCs since 1990. CFC-free inhalers formulations those are available in Europe and USA are listed in Table 3.

Table 3 : List of CFC-free inhalers available in Europe and USA.

\begin{tabular}{|c|c|c|}
\hline $\begin{array}{l}\text { Name of } \\
\text { product }\end{array}$ & Active Ingredient of Drug & Manufacturer \\
\hline Airomir & Salbutamol & $\begin{array}{c}\text { 3M Drug Delivery } \\
\text { Systems }\end{array}$ \\
\hline Asmol & Salbutamol & \\
\hline Epaq & Salbutamol & $\begin{array}{c}\text { 3M } \\
\text { Pharmaceuticals }\end{array}$ \\
\hline Ventolin & Albuterol Sulphate & Glaxo Smith Kline \\
\hline $\begin{array}{l}\text { Intal Forte CFC- } \\
\text { free }\end{array}$ & Sodium Cromoglycate & $\begin{array}{c}\text { Aventis } \\
\text { Pharmaceuticals }\end{array}$ \\
\hline Flixotide & Fluticasone Propionate & Glaxo Smith Kline \\
\hline Qvar & Beclomethasonedipropionate & $\begin{array}{c}3 \mathrm{M} \\
\text { Pharmaceuticals }\end{array}$ \\
\hline Tilade CFC-free & Nedocromil Sodium & $\begin{array}{c}\text { Aventis } \\
\text { Pharmaceuticals }\end{array}$ \\
\hline Seretide & $\begin{array}{l}\text { Salmeterolxinafoate \& } \\
\text { Fluticasone Propionate }\end{array}$ & Glaxo Smith Kline \\
\hline
\end{tabular}

\section{Trends in MDIS Technology [4,25]}

a. There has been much importance in the differences in effects of enantiomer of many medications and beta agonist adrenergic bronchodilators have received much attention. Recently levo salbutamol is present in the market.

b. Use of spacers to improve patient coordination with metered dose inhalers. Evidence indicates considerable intra and inter-subject variability for the inhalation.

c. The auto-haler TM is the first breath activated pressurized metered dose inhaler. Auto-haler solve the key problems of the pressurized metered dose inhaler (pMDI), does not rely on the patient's inspiratory efforts to aerosolize the dose of medication unlike dry powder inhalers.

\section{Dry Powdered Inhalers (DPIs)}

Dry powder system contain micronized drugs single or its mixes with a reasonable carrier, essentially as lactose, for conveyance to the lungs, which anticipates aggregation and increase flow properties of drugs $[4,25,26]$. When the patient activates the DPI and inhalers, airflow through the device makes shear and turbulence; air is brought into the powder bed and static powder mix is fluidized and enters the patient's airways. There, the drug particles isolate from the carrier particles and are carried deep into the lungs, while the larger carrier particles affect in the oropharynx and are cleared. Along these lines, deposition into the lungs is controlled by the patient's variable inspiratory airflow. The three principle variables Drug, Carrier, and device may influencing the act of pulmonary 
delivery of drug. In addition, DPIs are small, versatile device that can be effortlessly conveyed in a satchel or pocket. These devices are generally acknowledged inhaled delivery dosage form, especially in Europe, where they are at present utilized by roughly $40 \%$ of asthma patients. Absence of the necessity of propellant is leverage of DPIs over MDIs [27]. The fraction of the drug delivered to the site of activity by a DPI differs from $9 \%$ to $30 \%$. As of now there are two sorts of MDIs [4,25,28]. Different advertised items accessible in the market are shown in Table 4.

Table 4: List of DPI Marketed products.

\begin{tabular}{|c|c|}
\hline Name of Product & Manufacturer \\
\hline $\begin{array}{c}\text { Acu-Breathe (Respirics) } \\
\text { Aerolizer }\end{array}$ & Novartis \\
\hline Breezhaler & Novartis \\
\hline Chickhaler & Vectura \\
\hline Cyclohaler & Tera \\
\hline Diskhaler & GSK \\
\hline Diskus & GSK \\
\hline Podhaler & Novartis \\
\hline Pulmojet & Sanifi-Aventis \\
\hline Skyehaler & Skyepharma \\
\hline Solis & Sandoz \\
\hline Taifun & Akela \\
\hline Twisthaler & Schering/mercks \\
\hline Turbohaler & Astra Zeneca \\
\hline
\end{tabular}

Advantages of Dry Powder Inhalers (DPIs)

a. Larger drug available for pay loads per puff.

b. Blending is not requiring for it.

c. Enables use of small, flow-rate independent inhalers.

d. The particles readily disaggregate despite their small size.

e. Enables improved lung deposition, dose decrease variability and potential for condensed dose through enhanced dispersibility.

Trends in Dry Powder Inhalation Technology [29-31]

a. DPIs Performance can be adjusted through changes in the design of the device and furthermore changes in the powder formulation and designing. The strengths required in the process prompts the particle-particle interactions in the agglomerates and furthermore the forces playing a part in the de-agglomeration process.

b. Supercritical fluid technology (SCF) is connected to enhance the surface properties of the drug substance. c. Large porous particles have decreased inter-particulate forces because of their low density, the irregular surface structure or reduced surface free energy. Furthermore, these particles are accounted for to have enhanced aerodynamic behaviour in the airways, while phagocytises of the stored particles in the alveoli is lessened. In another approach, smaller porous particles $(3-5 \mathrm{~mm})$ have been utilized to enhance de-agglomeration and lung deposition.

d. Air classifier Technology has been recently utilized as a part of the devices to avoid agglomeration in devices.

\section{Current Trends}

Inspiromatic is delivered by Inspiro Medical, a portfolio organization of the Trendlines bunch, and is intended to replace hard-to-utilize nebulizers for youthful kids and additionally the elderly and individuals with specific handicaps. Inspiromatic has an internal microcontroller and flow sensor that identifies the ideal time to deliver the medication and consequently disperse the drug particles in the correct size without requirement for forceful Inhalation [32].

\section{Twisthaler}

This inhalation device is generally free of flow rates. It has been exhibited that with inspiratory flow between $28 \mathrm{l} / \mathrm{min}$ and $60 \mathrm{l} / \mathrm{min} 91 \%$ to $112 \%$ of the metered dose is delivered at the mouthpiece. The fraction of particles smaller than $6.5 \mu \mathrm{m}$ amount up to $40 \%$ at an inspiratory flow of $60 \mathrm{l} / \mathrm{min}$. moreover drug doses released from the Twisthaler $\AA_{\text {just change }}$ somewhat between each dosage. The twist haler is endorsed by momentosonefuroate [33].

\section{Nexthaler}

Cambridge Consultants is attempting to develop the upcoming era of dry powder inhaler for ChiesiFarmaceuticiSpA, a rising European pharmaceutical organization situated in Parma, Italy. The new inhaler intends to be the most straightforward toutilize dry powder inhaler available. The outline incorporates features to enhance performance and make the device discreet, natural to utilize and futuristic in appearance [34].

\section{HandiHaler}

It is utilized to deliver the substance of Spiriva inhalation Capsules containing the bronchodilator tiotropium, utilized for long-term treatment of chronic obstructive pulmonary disease (COPD) and other obstructive airways infection; to mitigate side effects of bronchospasm [35].

\section{Turbuhalers}

It has the dry powder pharmaceutical inside the tube-molded inhaler. They have a removable cover and a contorting base. It is a 'breath-activated' device means the dry powder medication is "sucked" from the device instead of "fired" like it is from different devices. Turbuhalers might be hard to use for young kids, or grown-ups who are short of breath. It is prescribed to have a puffer and spacer accessible for crises [36]. 


\section{Easy Haler}

The Easy haler $\AA$, is produced and patented by Orion, is an environment friendly and efficient, simple to use for the treatment of respiratory sicknesses, for example, asthma and chronic obstructive pulmonary disease (COPD). Orion aims to expand the product family of inhalable Easy haler® drugs utilized for treating asthma and COPD [37]. Currently used delivery devices and drugs utilized inhaled drugs for asthma in US is shown in Table 5 and future improved formulations of DPIs are shown in Table 6.

Table 5: Currently used devices and drugs for Asthma in US.

\begin{tabular}{|c|c|}
\hline $\begin{array}{c}\text { Active Pharmaceuticals } \\
\text { Ingredients }\end{array}$ & DPIs \\
\hline Formoterol & Fordilaeroliser (Novartis AG) \\
\hline Salmeterol & Diskus (GSK) \\
\hline Tiotropium & $\begin{array}{c}\text { Spiriva Handihaler } \\
\text { (BoehringIngelheim) }\end{array}$ \\
\hline Budenoside & Pulmicort Flexhaler (Astra Zeneca) \\
\hline Fluticasone & Diskus (GSK) \\
\hline Mometasone & Asmenex Twisthaler (Schering- \\
\hline
\end{tabular}

Table 6: Future DPIs (approved or in development stage).

\begin{tabular}{|c|c|c|}
\hline Device & Manufacturer & Drug \\
\hline Aspirair/Active & Vectura & $\begin{array}{l}\text { Apomorphine } \\
\text { hydrochloride }\end{array}$ \\
\hline Omnihaler/active & $\begin{array}{l}\text { Innoveta Biomeds } \\
\text { Ltd. }\end{array}$ & - \\
\hline Tanifun & Focus inhalation & Fentanyl \\
\hline Cyclovent & Pharmachemie & Opioids \\
\hline $\begin{array}{l}\text { Spiros/breath } \\
\text { activated active }\end{array}$ & Dura & Albuterol sulphate \\
\hline Acu-breath & Respirics & $\begin{array}{l}\text { Fluticasone } \\
\text { propionate }\end{array}$ \\
\hline Swinhaler & $\begin{array}{c}\text { Otsuka } \\
\text { pharmaceutical Co. } \\
\text { Ltd. }\end{array}$ & $\begin{array}{l}\text { Procaterol, } \\
\text { budesonide }\end{array}$ \\
\hline $\begin{array}{l}\text { Procaterol, } \\
\text { budesonide }\end{array}$ & Novartis Pharma & Formoterol \\
\hline Technohaler/passive & $\begin{array}{l}\text { InnovetaBiomeds } \\
\text { Ltd. }\end{array}$ & - \\
\hline
\end{tabular}

Screening Models for Pulmonary Drug Delivery Systems

Several models are presented for preclinical investigation of pulmonary drug absorption and deposition. The complexity of the models range from permeability screening experiments in cell culture models to in vivo pharmacokinetic analysis in animals. The design of the experiments comprises both selection of the most relevant biological model for the specific issue, and the selection of a drug delivery system i.e. appropriate for the amount of test material available and that can selectively deposit a defined dose of the drug to the intended lung region. A combination of in vitro and in vivo models is needed to elucidate the mechanisms, rate, and extent of absorption, as well as the distribution, metabolism and elimination of a drug after pulmonary administration [1].

\section{Cell Culture Models}

The inaccessibility and heterogeneous composition of the airway epithelium makes it difficult to mechanistically evaluate pulmonary cellular integrity and physiological function. For investigation of drug transport mechanisms, precise dosing and sampling, as well as defined local drug concentration and surface area of exposure, are important parameters that need to be controllable and reproducible. Therefore, a variety of airway and alveolar epithelial cell culture models of animal and human origin have been established as in vitro absorption models. The models include both continuous cell cultures, primary cell cultures and air-interface cultures [38].

Continuous Cell Cultures: They are reproducible and easily utilize than primary cell cultures but they frequently don't have the differentiated morphology and the biochemical characteristics of the original tissue. There are a small number of cell lines resulting from alveolar epithelial cells. A549 is a type II alveolar epithelial cell line that originates from human lung adenocarcinoma. It can be very helpful in metabolic and toxicological studies but it is less interesting as a drug delivery model because A549 cells do not form stretched monolayer's [39].

Primary Cell Cultures: The primary cell cultures more closely resemble the native epithelia and used as model for pulmonary drug delivery, but are less reproducible and more time consuming to work with compared to the cell lines, which make them less suitable for permeability screening purpose. Type II pneumocytes for primary culture can be removed from the lung. Human cells are the mainly representative of the clinical circumstances, but they are less available than cells from other mammals. Human type II pneumocytes are removed from normal lung tissue of patients undergoing partial lung resection. In culture, the cells experience segregation into type I-like cells, as indicated by morphological and histochemical change. In premature stages of the cell culture, the cells create elevated levels of surfactant protein $C$ and little levels of caveolin 1 , a marker of type I pneumocytes, and on the other hand at later stages. On day 8 of culture, the cells form a tight monolayer consisting mainly of type I cells and some interspersed type II cells, with TEER $>2000 \Omega \mathrm{cm} 2$ and potential difference $>10 \mathrm{mV}$ [40].

Air-Interface Cultures: AIC models are permitting aerosol particles to place straight onto semi-dry apical cell surface. Drug deposition and dissolution take place in a small volume of cell lining fluid, a circumstances that mimics more directly 
deposition on the lung surface in vivo. The AIC show greater similarity to airways epithelial morphology, with glycoprotein discharge, more prominent microvilli and the construction of a pseudo stratified layer of columnar cells, while the liquidcovered culture created a monolayer of cells.

\section{In Vivo Animal Models}

In vivo pharmacokinetic experiments in animals provide data on the fate of a drug and its metabolites in the body by assessment of the drug concentration in plasma or tissues. Drug exiting device Inhaled dose Systemic exposure Alveolar deposition Pulmonary deposition Tracheal/Bronchial deposition Firstpass metabolism/ Not absorbed from GI-tract Extra pulmonary deposition Exhaled dose Distribution/Metabolism/Elimination Absorbed AM (phagocytosis by alveolar macrophages) MC (Mucociliary clearance metabolism). By contrast, small rodents, mice models for preliminary studies on pulmonary drug delivery because they can be used in large numbers. Mice have been used less often for assessing pulmonary release of systemically performing drugs because pharmacokinetic studies are not optimally perform in mice.

Owing to its small size, one mouse can offer only one blood sample at a time $(1 \mathrm{ml}$ whole blood sample is withdrawn by cardiac puncture and mouse euthanasia must be done at each time point of the plasma drug concentration-time curve. Guinea pigs have been generally used as an animal form of allergic asthma and infectious diseases (e.g., tuberculosis) since the airway anatomy and the respond to inflammatory stimuli are similar to the human case. The dissimilar mammals do not show to present related Mucociliary clearance and alveolar macrophage morph metric. In large mammals, the rate of mucus permission in millimetres per minute is elevated compared with small rodents. Though, huge mammals also have longer airways than minute rodents and thus, worldwide, the bronchial permission of inhaled particles is comparatively slow in humans $(>24 \mathrm{~h})$.

\section{Cascade Impactors}

It determines the aerodynamic activity of aerosol particles by size-separating the dose in impactor plates. It gives up valuable aerosol parameters such as the fine particle fraction, mass median aerodynamic diameter. In vitro particle sizing data obtained from impactors plan first at scheming the quality of the pharmaceutical product and next at provide an analysis tool for product improvement. It is projected that outcome from cascade impactors forecast human lung deposition data as particle aerodynamic size determine the deposition of aerosol in the respiratory tract.

\section{Passive Inhalation}

During the inhalation of aerosolised drugs, all the mammals are kept awake and allowed to breathe normally. Aerosolised drugs are delivered using an aerosolisation chamber in whole body exposure systems, head-only or nose-only exposure systems. The devices is generally used for generating aerosols are nebulizers. Passive inhalation is principally used in the mouse and less frequently in heavy animals (rat, guinea-pig, dog). This method is more representative of drug delivery to the human lungs than intratracheal instillation of high volumes of liquids. The drug concentration in the aerosol is determined by sampling the test atmosphere and quantifying the drug in the sample.

\section{Whole Body Exposure Systems}

In this system, animals are placed in a sealed plastic box that is connected to a nebuliser or a generator of dry powder aerosol. Although this system allows a less stressful pulmonary drug administration to an important number of animals, there is potential drug absorption across the skin after deposition on the animal fur, from the nasal mucosa and from the gastrointestinal tract.

\section{Head-Only or Nose-Only Exposure Systems}

In these systems, the animal is attached to the exposure chamber and only the nose or the nose is in contact with the aerosol device. The systems can be designed for delivering drugs to one or to several animals. Compared with the whole body exposure system, the head-only or nose-only exposure systems offer different advantages. The low volume of the aeroionisation chamber reduces the amount of drug needed to generate the aerosol.

\section{Intranasal administration}

This is mostly known for local drug delivery to the nasal mucosa but it can also be used for intrapulmonary drug administration in mice. It is performed on the anaesthetised mouse kept in a vertical position. With the help of a micropipette, the solution is deposited on a nostril and is simply aspirated in respiratory airways during breathing. Use of a small volume of solution restricted drug administration to the nasal cavity but that the use of a larger volume of solution allowed a deeper administration to be reached in lung upper airways.

\section{Recent Advancements In Formulation of Pulmonary Drug Delivery}

Effective inhalable meds are formed by drug formulation and designing. Formulation stability is another trouble in producing pulmonary drug delivery. Formulation is in charge of keeping drug in pharmacologically active state, it must be proficiently delivered into the lungs, to the fitting activity on the specific site and stay in the lungs until the coveted pharmacological effect happens. Here a formulation that is retained in the lungs for the proper time allotment and avoids the clearance mechanisms of the lung may be necessary. A few factors have been incorporated into support of developing nasal formulations containing liposomes, microspheres and nanoformulations for intranasal drug delivery. In fact, it is not clear if those formulations increase 
drug absorption by transporting encapsulated drug across the membrane or just because they improve the nasal retention time and stability of the drug. However, their utilization is in extensive growth and the outcomes have been exceptionally skilled.

\section{Prodrugs}

Prodrug is used to explain compounds that undergo biotransformation prior to exhibiting their pharmacological effect. Throughout the years, prodrugs have been used to decrease the bad taste of the drug, poor solubility, insufficient stability, incomplete absorption across biological barriers and metabolism to inactive or toxic species. Intranasal drugs are can administered as solutions or as powder form which need to undergo a dissolution process before absorption. Lipophilic drugs easily diffuse through the bio membranes, but they are poorly soluble in water. So they have to be administered as a prodrug with higher hydrophilic character in order to make possible the manufacturing of an aqueous nasal formulation with a desirable concentration. Once in the blood stream, the prodrug must be quickly converted to the parent drug. In contrast, very hydrophilic polar drugs may not have ability to cross biomembranes. Thereby, if they are administered as prodrugs with higher lipophilic character, the penetration through the membrane may increase. For instance, L-Dopa is poorly soluble in water, so it is very difficult to develop a corresponding intranasal aqueous formulation with an effective dose. Produced various prodrugs of L-Dopa and observed that their solubility enhanced significantly in contrast with the pure drug, allowing, hence, the development of adequate nasal formulations. Furthermore, their nasal administration resulted in an accelerated and complete absorption to the systemic circulation, where quick conversion to L-Dopa takes place. Similar report was obtained for testosterone which is also poorly soluble in water $[41,42]$.

\section{Enzymatic inhibitors}

Nasal mucosa and nasal mucus layer have a huge variety of enzymes. Hence they act as enzymatic barriers for nasal drug delivery. Various approaches have been used to avoid enzymatic degradation, including the use of proteases and peptidases inhibitors. For example, bestatine and comostate amylase are used as aminoptidases inhibitors and leupeptine and aprotinin as trypsine inhibitors probably involved in the degradation of calcitonin. Furthermore, bacitracin, amastatin, boroleucin and puromycin have been used to avoid enzymatic degradation of drugs such as leucineenkephalin and human growth hormone [41].

\section{Absorption enhancers}

Hydrophilic drugs may be poorly permeable across the nasal epithelium and may show an insufficient bioavailability and therapeutic efficacy. Their absorption is greatly improved by administered in combination with absorption enhancers which induce epithelial barrier by modifying the phospholipidic bilayer. In intranasal drug delivery, absorption enhancers most used are surfactants (laureth-9), bile salts, fatty acids (taurodihydrofusidate) and polymeric enhancers (chitosan, cyclodextrins, poly-Larginineand aminatedgelatin)[42-46].

\section{Novel drug formulations}

Several factors have been included in support of developing nasal formulations containing liposome, nanoparticles and microspheres for intranasal drug delivery. In fact, it is not clear if those formulations increase drug absorption by transporting encapsulated drug across the membrane or just because they increase the nasal retention time and stability properties of the drug.

Liposomes: Liposomes are a type of vesicles that contains both of numerous, few or only one phospholipid bilayers enclosing one in or more aqueous compartments in which drugs and different substances may be put stored. Presently a day, they have been examined as a vehicle for sustained release therapy in the lung disease treatment, gene therapy and as a technique for delivering therapeutic agents to the alveolar surface for the treatment of systemic diseases. Liposomal drug delivery systems introduce different focal points, for example, the effective encapsulation of small and large molecules with an extensive variety of hydrophilicity and pKa values. In fact, they have been found to enhance nasal absorption of peptides, for example, insulin and calcitonin by expanding their membrane penetration. This has been ascribed to the expanding nasal retention of peptides, insurance of the entrapped peptides from enzymatic degradation and mucosal membrane disruption. Incorporated insulin in liposomes coated with chitosan and carbapol and administered them intranasally to rats. The report demonstrates that this formulation was effective and that its mucoadhesive property is a reasonable choice for a sustained release of insulin $[24,47,48]$.

Nanoparticles: Nanoparticle systems are being investigated to improve drug delivery and intranasal drug administration. Nanoparticles are solid particles having a diameters ranging from 1-1000 nm. They consist of macromolecular materials and which are therapeutically used as adjuvant in vaccines or as drug carriers, in which the active substance is entrapped, dissolved, encapsulated, adsorbed or chemically attached. Nanoparticles have several advantages due to their Nano size property, but only the small nanoparticles is able to penetrate the mucosal membrane by Para cellular route and in a limited quantity, since the tight junctions are in the order of 3.9-8.4 A. There are several studies have been suggested that nanoparticle systems can be preferably suited as a vehicle for sustained release therapy. Sustained release from therapeutic aerosol can prolong the residence of an administered drug in the airways or alveolar region, minimize the risk of adverse effects by decreasing its systemic absorption rate, and increase patient compliance by reducing dosing frequency. Nanoparticle systems are also suitable for the delivery of nasal vaccines $[41,49]$. 
Concept of Targeted Delivery and in Vivo Behaviour of Nanoparticles

Nanoparticles are characterized as particles with submicron sizes in diameter. Since the mid-2000s, a wide assortment of nanoparticles has been produced as drug carriers for biomedical applications. Different materials have been utilized for the manufacture of nanoparticles. Nanoparticles regularly share their unique physical properties due to their submicron estimate, and these characteristics have been exploited for disease-specific drug delivery. Significantly, nanoparticles have a bigger surface area than micro materials with similar total masses. It permits nanoparticles to have a superior opportunity to have contact with the surrounding tissues and cells, subsequently increasing the efficiency of cellular delivery. Moreover, systemically injected nanoparticles in vivo generally show enhanced accumulation to the pathological lesions found in tumours, hemorrhagic diseases, and inflammatory diseases. These findings suggest that nanoparticles have perfect properties to be utilized as imaginative carriers for drug delivery.

\section{Microspheres}

This technology has been useful in designing of nasal drug delivery formulations. Microspheres are generally based on muco-adhesive polymers like chitosan, alginate, which provide various advantages for intranasal drug delivery. Moreover, microspheres also protect the drug from enzymatic metabolism and gives sustain drug release, thereby prolonging its effect [41].

\section{Mucoadhesive Drug Delivery Systems / Mucoadhesion}

MCC is one of the very important limiting steps for nasal drug delivery, because it decreases the time allowed for drug absorption. So these systems improving the nasal drug absorption, and also prolonging the contact time between nasal mucosa and drug. Mucoadhesion represents the attachment of the drug delivery to the mucus, involving an interaction between mucin and a synthetic or natural polymer known as mucoadhesive. The sequential events that occur during this mucoadhesion include different steps. First mucoadhesive systems absorb water from mucus layer and get wet and swell. Following this, the polymer intimately penetrates into the mucus and, hence, localizes the formulation in nasal cavity, increase the drug concentration gradient across the epithelium. This system is useful in intranasal drug delivery are alginate, cellulose and alginate or its derivatives [41].

\section{Dendrimers}

Dendrimers are repetitively branched molecules, and they exhibit improved physicochemical properties compared with typical macromolecules. In general, Dendrimers are highly monodisperse nanoparticles, and the size and surface functionality of the final formulations are precisely controllable. Dendrimers are carrying a large amount of drugs, and the PEG modified dendrimer shows favourable pulmonary absorption after inhalation. Thus, dendrimers have been widely used for the delivery of therapeutics for chronic lung diseases, and anticancer agents, antibiotics, and steroids have been reported to be delivered to the lungs by dendrimers.

\section{Latest Developments}

Aradigm was developed AERx pulmonary technology, which help in transferred insulin and morphine into the pulmonary route. On the other side, Alkermes has prepared an inhalation technology, which would enable us to deliver dry powder of small molecules, peptide and protein drug particles to the deep lungs. Nektar Therapeutic in conjunction with Pfizer began dosing first diabetic patients for the phase III clinical trial for inhalable insulin Exubera. They are also developing other active pharmaceuticals molecules to be delivered by using its proprietary delivery technology. The different problems faced by pulmonary drug delivery systems, many peptide and protein drugs are currently investigated for potential systemic absorption by pulmonary system, and that includes insulin, calcitonin, luteinizing-hormone-releasing hormone analogs, granulocyte colony-stimulating factor, and human growth hormone.

\section{Current Applications of Pulmonary Drug Delivery Systems}

\section{Applications of pulmonary drug delivery in Asthma and COPD}

Asthma is a chronic lung disease that is categorized under inflammation and narrowing of airways. Asthma causes periods of wheezing, breath shortness, and coughing. Asthma affects people of all ages, but it most often starts in childhood. COPD means chronic obstructive pulmonary diseases, which is correlated to smoking, chronic bronchitis and emphysema. Today's inhaled drug delivery market is conquered by the three main classes of drug such as anticholinergic, bronchodilators and corticosteroids. All these three classes of drugs are only given by pulmonary route. Levosalbutamol inhalers are present in the market to treat asthma. Titropium inhalers are present in market to teat COPD $[1,50,51]$.

\section{Recent role in Pulmonary Delivery in Patients on Ventilators}

Nowadays to improve inhalation coordination of patient devices are mostly used like Baby mask. This mask is attached to spacer for small tidal volumes and low inspiratory flow rates infant and young Childers. We can easily give medication to child up to 2 years by using baby masks this is recent advancements in applications of pulmonary drug delivery.

\section{New use of Pulmonary Delivery in Diabetes}

Diabetes is a syndrome of disordered metabolism and hyperglycaemia resulting from an insufficiency of insulin secretion or resistance which cause the blindness, kidney disorder, nerve damage, heart attack and other health problems. The most common form of this therapy is twice-daily 
subcutaneous injections of insulin. This type of treatment may cause pain and as a result encourages noncompliance by up to half of the diabetics. Various companies are working on insulin inhalers than any other insulin delivery option. Insulin inhalers would work as asthma inhalers. The products fall into two main groups the dry powder formulations and solution. E.g. Novel pMDI formulations for pulmonary delivery of proteins [1,52-57].

\section{Application of Pulmonary Delivery in Migraine}

Drug Ergotamine is choice for migraine. This drug used successfully to treat migraine headache via metered dose inhaler (MDI) [58].

\section{Application of Pulmonary Delivery in Angina Pectoris}

Angina pectoris is not a disease itself it is symptoms of myocardial ischemia and it is arises as a result of imbalance between oxygen supply and demand of myocardium. Nitroglycerine is a drug of choice for angina pectoris, and is given through sublingual route. Isosorbide aerosol has also been reported useful in hypertensive emergency $[1,58]$.

\section{Role of Pulmonary Delivery in Vaccines}

While there was moderate interest in aerosol vaccination 1520 years ago, progress toward application has rarely seen. About 100vaccinesare approved in the U. S. About half of these prevent respiratory diseases, yet all are currently injected. Recently inhaled measles vaccine given by nebulizer [55].

\section{Use of Pulmonary Drug Delivery System Intransplantation}

Inhalation route play important role in transplantation. Acute and chronic rejections are major problems compromising transplant and patient survival. Aerosolized cyclosporine is useful for reducing the risk of acute rejection [56-58].

\section{Applications of Pulmonary Delivery in Pulmonary Arterial Hypertension}

In 2004, the FDA approved Ventavis (iloprost), an inhaled treatment for pulmonary arterial hypertension, made by CoTherix (South San Francisco, CA, USA). In pulmonary arterial hypertension, severe restriction of blood vessels results in early death. Iloprost naturally dilates blood vessels [50, 59].

\section{Application of Pulmonary Drug Delivery in Cancer Chemotherapy}

Lung cancer is the leading cause of cancer death and inhaled chemotherapy is approach for the treatment of lung cancer. A multicentre phase I clinical trial is evaluating doxorubicin $\mathrm{HCl}$ inhalation solution in lung cancer patients. As many as 4lakh lung cancer patients a study is going on aerosolized paclitaxel solution to mice with lung tumours. The treatment significantly reduced lung tumours and prolonged survival. Aerosol drug delivery of the anticancer agents like difluoromethylornithine and 5-fluorouracil reduced lung tumours in mice $50 \%$ and 60 $\%$, respectively. Interleukin-2 stimulates immune function in cancer patients, but injections cause fever, malaise, and locals welling [50].

\section{Gene Therapy via Pulmonary Route}

Recent research in application of pulmonary drug delivery. It holds great potential for the treatment of various acquired and inherited pulmonary diseases. The main aim of this therapy is treatment of cystic fibrosis. Cationic-lipid mediated CFTR gene transfer can significantly influence the underlying chloride defect in the lungs of patients with CFC. There are many problems to be overcome before clinical applications are practical. Some of these are safe, successful transfer of sufficient genetic material to appropriate tissue, adequate gene expression, maintenance of expression over time, and efficacy of expression [60].

\section{Delivery of Pentamidine by Pulmonary Route}

Protozoan Pneumocystis carinii (PCP) is major cause of Pneumonia is Patients with acquires immunodeficiency syndrome. Aerosol pentamidine is useful in treating mild PCP and prophylaxis against PCP [61].

\section{Inhaled Drug Delivery for Tuberculosis Therapy}

Tuberculosis (TB) is infectious disease cause by Mycobacterium tuberculosis. One third of the population is suffered from TB, and new infections occur at a rate of one per second. New drugs or delivery systems that will decrease the spread of tuberculosis and slow down or prevent the development of drug-resistant strains are seriously required. Lung lesions containing large numbers of bacteria are poorly vascularised. Conventional therapy given by the parenteral or oral routs May give sub therapeutic levels of ant tuberculosis (anti-TB) drugs. Administering drugs by the pulmonary route to the lungs allows maximum drug concentrations in the vicinity of the selesions. Supplementing conventional therapy with inhaled anti-TB therapy may allow therapeutic concentrations of drug to penetrate effectively into lung lesions and treat the resident mycobacteria [62]

\section{Nicotine Aerosol for Smoking Cessation}

Smoking is injurious to the health. From ancient times people smokes cigarette and get addicted with smoking. The reason for cigarette smoking is Nicotine addiction, and nicotine replacement is appealing as a means of reducing cigarette use to ultimately achieve cessation.

\section{Diagnostic Application Pulmonary Drug Delivery}

It is use for therapeutic purpose as well as for diagnosis purpose. For example, inhalation of aerosols of methacholine and histamine is responsive in asthma [63].

\section{Current Use of Pulmonary Delivery of Opioids as Pain Therapeutics}

To avoid pain associated with inject able pain killer pulmonary opioid delivery is better alternative. Clinical data of inhaled opioids were focused on treatment of dyspnoea. 
They showed that inhalation of various opioids compounds are safe even in severely ill patients. The advent of specialized and efficient pulmonary drug delivery systems make easy evaluation of inhaled opioids, such as morphine and fentanyl, for management of severe pain associated with surgery or malignant disease [64].

\section{Conclusion}

Among the various drug delivery approaches, pulmonary drug delivery is one of the oldest drug delivery systems it is widely used due to its potential advantages. This approach is based on principle of inhalation of medication through the lungs which then enters the bloodstream through the alveolar epithelium. A major determining factor of this route is optimum particle size, which regulates the targeted delivery of drug to lungs. Various drugs which produce GI irritation can be administered by pulmonary route with greater efficiency. The delivery device plays a major role in the efficiency of pulmonary delivery. The most commonly used devices for respiratory delivery are nebulizers, metered-dose inhalers, and dry powder inhalers; these can be made adaptable for delivery of protein and peptide drugs. Inhalable nanocarrier systems offer numerous advantages owing to its decreased particle size. Carriers like microparticles, nanoparticles, liposomes etc. can be used in pulmonary delivery. DPI provides various benefits like its ease in use, cheapness, robustness. Problem to deliver large amount of powder (around $50 \mathrm{mg}$ ) in one breath and to maintain stability of powder formulation are major challenges with DPI. Thus understanding of challenges and overcoming, it coupled with anatomical and biopharmaceutical basics helps in reducing the technical gaps and hence encourages the future advancement in formulation of new improved strategy for pulmonary drug delivery.

\section{References}

1. Sheikh S (2011) International Journal of Pharma Research and Development 2(12): 018.

2. Micheal $T$ (2000) Newhouse, Encyclopedia of Pharmaceutical Technology. ( $2^{\text {nd }}$ edn), Dekker, New York, Informa Healthcare USA, 19: 1279-1285

3. Akwete AL, Gupta PK (1997) Delivery of Biotherapeutics by Inhalation Aerosol. In Inhalation Delivery of Therapeutic Peptides and Proteins, Marcel Dekker, Inc., New York, USA, pp. 151-231.

4. World Health Organization (2013) Global Tuberculosis Report 2013. World Health Organization, Geneva, Switzerland, p. 6-27.

5. World Health Organization (2007) Global Surveillance, Prevention and Control of chronic Respiratory Diseases: A Comprehensive Approach. World Health Organization Geneva, Switzerland, p. 12-36.

6. Halbert RJ, Natoli JL, Gano A, Badamgarav E, Buist AS, et al. (2006) Global burden of COPD: systematic review and meta-analysis. Eur Respir J 28: 523-532.

7. Masoli M, Fabian D, Holt S, Beasley R (2004) Global Initiative for Asthma. P Allergy 59: 469-478.

8. Ley B, Collard HR (2013) Epidemiology of idiopathic pulmonary fibrosis. Clin Epidemiol 5: 483-492.
9. Raghu G, Weycker D, Edelsberg J, Bradford WZ, Oster G (206) Am J Respir Crit Care Med 174(7): 810-816.

10. Ruppert C, Schmidt R, Grimminger F, Suzuki Y, Seeger W, et al. (2002) Bio Conjug Chem 13: 804-811.

11. Durham AL, Caramori G, Chung KF, Adcock IM (2016) Targeted antiinflammatory therapeutics in asthma and chronic obstructive lung disease. Transl res 167(1): 192-230.

12. Fujita Y, Takeshita F, Kuwano K, Ochiya T (2013) RNAi Therapeutic Platforms for Lung Diseases. Pharmaceuticals 6(2): 223-250.

13. Meyer KC (2014) Diagnosis and management of interstitial lung disease. Transl Respir Med 2: 4.

14. Tangri P (2001) Approaches To Pulmonary Drug Delivery Systems. International Journal of Pharmaceutical Sciences and Research 2(7): 1616-1622.

15. Banker GS, Rhodes TR (2002) Modern Pharmaceutics. ( $4^{\text {th }}$ edn), Marcel Dekker, New York, USA, pp. 529-586.

16. Karhale A, Chaudhari HS, Ughade PL, BaviskarDT, Jain DK (2012) International Journal of Pharmatech Research Coden p. 4.

17. Cole RB, Mackay AD (1990) Concepts of Pulmonary Physiology. In Essentials of Respiratory Disease, New York, Churchill Livingstone, USA, p. 49-60.

18. Hindle M, Byron PR (1999) Int J Pharm pp. 116-169.

19. www.cipladoc.com

20. Ozer A (2007) Alternative applications for drug delivery: Nasal and pulmonary routes. Nanomaterials and Nanosystems for Biomedical Applications pp. 99-112.

21. Tronde Ann (2002) Pulmonary drug Absorption. Acta Universities Upsaliensis pp. 86-275.

22. Newman SP (1990) Metered dose pressurized aerosols and the ozone layer. Eur Respir J 3: 495-497.

23. David AE, Abdelaziz B, Robert L (1998) Cellular Aspects of Lung Function. J Appl Physiology 85: 379-385.

24. McElvaney NG, Hubbard RC, Birrer P Lancet (1991) Aerosol alpha 1-antitrypsin treatment for cystic fibrosis. Lancet 337: 392-394.

25. Paul J Atkins, Timothy M Crowder The Design and Development of Inhalation Drug Delivery Systems. Modern pharmaceutics by Marcel Dekker p. 1-31.

26. R Sunitha (2011) International Journal of Pharmaceutical, Chemical and Biological Sciences 1(1): 66-82.

27. Chawla A, Taylor KMG, Newton JM, Johnson MCR (1994) Int J Pharm 108: 233-240.

28. Ogden, Jill, Rogerson C, Smith I (1996) Issues in pulmonary delivery. In Scrip Magazine 1996: 56-60.

29. Kohler D (1994) Journal of Aerosol Medicine 7(4): 307-314.

30. Kinnula V, Cantell K, Mattson K (1990) European Journal of Cancer 26: 740-741.

31. Martin RJ, Boguniewicz M, Henson JE (1993)148:1677-1682.

32. http://www.misgav-venture.com/news-in.asp?num=337

33. http://www.admit-online.info/index.php?id=131\&L=0

34. http://www.cambridgeconsultants.com/projects/chiesinexthaler

35. http://www.inhousepharmacy.vu/p-200-spirivahandihaler.aspx

36. http://www.asthmafoundation.org.au/Turbuhalers.aspx 
37. http://www.orion.fi/en/Research-anddevelopement/ResearchAreas-/Inhaled medicinal products-the-platform/

38. Elbert et al., 1999; Foster et al., 2000; Morimoto et al., 1993; Winton et al., 1998; Yamashita et al., 1996.

39. Lin H Li, Cho HJ (2007) J Pharm Sci 9(6): 341-350.

40. Blank F, Rothen Rutishauser BM, Schurch SJ (2006) Aerosol Med 19(3): 392-405.

41. Anaísa Pires (2009) J Pharm Sci 12(3): 28 -311.

42. Higuchi T, Stella V (1975) Prodrugs as Novel Drug Delivery Systems. American Chemical Society, Washington, DC, USA

43. Hersey SJ, Jackson RT (1987) J Pharm Sci 76: 876-879.

44. Mishima M, Wakita YJ (1987) Pharmacobiodyn 10: 624-631.

45. Baglioni C, Phipps RJ (1990) J Interferon Res 10: 497-504.

46. Illum L, Farraj NF, Davis SS (1994) Pharm Res 11: 1186-1189.

47. Jain AK, Chalasani KB, Khar RK, Ahmed FJ, Diwan PV (2007) J Drug Target 15: 417-427.

48. Law SL, Huang KJ, Chou VHY, Cherng JY (2001) J Liposome Res 11: 164 174

49. Fernandez Urrusuno R, Romani D, Calvo P, Vila JatoJl, Alonso Mj (1999) Development Of A Freeze Dried Formulation Of Insulin-Loaded Chitosan Nanoparticles Intended For Nasal Administration. STP Pharma Sciences 9(5): 429-436.

50. John S (2006) Expert Opinion on Emerging Drugs 11(4): 609-619.

51. Mc Grew, (2003) Harrison Principles of Internal medicine. Hill medical publication17: 1596-1636.

52. David AE, Andre XV, Jonathan M, Nicolas Tsapis (2004) Recent Advances Related to the Systemic Delivery of Therapeutic Molecules by
Inhalation. Modern pharmaceutics marcel Dekker, Harvard University, Cambridge, Massachusetts, USA, p. 1-10.

53. David RO, Geremia BB, Bernard Z (2002) Future options for insulin therapy, current science pp. 1548-1554.

54. Gowthamarajan K, Giriraj TK (2003) Oral Insulin-Fact or Fiction resonece p. 38-40.

55. Al Tabakha MM, Alerid A (2008) Indian journal of pharmaceutical science pp. 278-284.

56. Naryani R (2011) Organ 15910: 12-16.

57. Jaleh V (2007) Recent Patents on Endocrine, Metabolic \& Immune Drug Discovery 1: 25-40.

58. Gabrielle PA, Francis VB, Karim A (2009) International Journal of Pharmaceutics 365: 162-169.

59. Robyn J Barst (1998) Acc Current Journal Review p. 61-63.

60. Justin Hanes, Michelle Dawson, Yah el Harel, Junghae Suh, Jennifer Fiegel (2004) Johns Hopkins University, Baltimore, Maryland, USA, Gene Delivery to the Lung, Modern pharmaceutics, Marcel Dekker p. $1-51$.

61. Montgomery AB (2004) Aerosolized Pentamidine for Treatment and Prophylaxis of pneumocystis carinii Pneumonia in Patients with Acquired Immunodeficiency Syndrome. Modern pharmaceutics, Marcel Dekker, USA, p. 1-14.

62. Pavan M, Chenchen W, Anthony JH (2009) Pharmaceutical Research 26: 11.

63. (2004) Practical Aspects of Imaging Techniques Employed to Study Aerosol deposition and Clearance, modern pharmaceutics Marce Dekker, USA, p. 38-43.

64. Stephen JF, Babatunde AO (2006) Advanced Drug Delivery Reviews 58: 1076-1088.

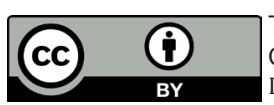

This work is licensed under Creative Commons Attribution 4.0 Licens

DOI: 10.19080/IJOPRS.2018.02.555593 